\title{
Recognizing the hidden: strengthening the HIV surveillance system among key and priority populations in Mozambique
}

\author{
Cynthia Semá Baltazar ${ }^{1,2^{*}+} \mathbb{D}$, Makini Boothe ${ }^{2 \dagger}$, Denise Chitsondzo Langa', Isabel Sathane ${ }^{3}$, Roberta Horth ${ }^{4}$,
} Peter Young ${ }^{5}$, Nick Schaad ${ }^{4}$ and Henry F. Raymond ${ }^{6,7}$

\begin{abstract}
High quality, representative data from HIV surveillance systems that have country ownership and commitment are critical for guiding national HIV responses, especially among key and priority populations given their disproportionate role in the transmission of the virus. Between 2011 to 2013, the Mozambique Ministry of Health has conducted five Biobehavioral Surveillance Surveys among key populations (female sex workers, men who has sex with men and people who inject drugs) and priority populations (long distance truck drives and miners) as part of the national HIV surveillance system. We describe the experience of strengthening the HIV surveillance system among those populations through the implementation of these surveys in Mozambique. We document the lessons learned through the impact on coordination and collaboration; workforce development and institutional capacity building; data use and dissemination; advocacy and policy impact; financial sustainability and community impact. Key lessons learned include the importance of multisectoral collaboration, vital role of data to support key populations visibility and advocacy efforts, and institutional capacity building of government agencies and key populations organizations. Given that traditional surveillance methodologies from routine data often do not capture these hidden populations, it will be important to ensure that Biobehavioral Surveillance Surveys are an integral part of ongoing HIV surveillance activities in Mozambique.
\end{abstract}

Keywords: HIV, Surveillance, Biological and behavioral surveys, Mozambique, Key population, Priority population, Lessons learned

\section{Background}

Mozambique has a generalized HIV epidemic with a prevalence of $13.2 \%$ among adults aged $15-49$ years old [1]. Despite the implementation of activities to prevent and control the epidemic, HIV remains one of the greatest public health challenges in the country. Early in the HIV epidemic in Mozambique, like elsewhere in sub-

\footnotetext{
* Correspondence: cynthiasema@yahoo.com; cynthia.baltazar@ins.gov.mz ${ }^{\dagger}$ Cynthia Semá Baltazar and Makini Boothe contributed equally to this work. 'Instituto Nacional de Saúde (INS), Maputo, Mozambique

${ }^{2}$ Department of Public Health and Primary Care, Faculty of Medicine and Health Sciences, Ghent University, Ghent, Belgium

Full list of author information is available at the end of the article
}

Saharan Africa, disease monitoring relied on sentinel surveillance in priority groups, such as pregnant women, and later nationally representative population-based household surveys [1, 2]. A limitation of populationbased household surveys is that they are often unable to sufficiently sample numbers of vulnerable populations such as migrants and mobile populations, displaced persons, or key populations (KP), such as sex workers, men who have sex with men, people who inject drugs, transgender people, and their sexual partners, who disproportionately contribute to HIV transmission due to high risk sexual and drug use behaviors [3-5]. Additionally, because of stigma and discrimination, individuals in

(c) The Author(s). 2021 Open Access This article is licensed under a Creative Commons Attribution 4.0 International License, which permits use, sharing, adaptation, distribution and reproduction in any medium or format, as long as you give appropriate credit to the original author(s) and the source, provide a link to the Creative Commons licence, and indicate if changes were made. The images or other third party material in this article are included in the article's Creative Commons licence, unless indicated otherwise in a credit line to the material. If material is not included in the article's Creative Commons licence and your intended use is not permitted by statutory regulation or exceeds the permitted use, you will need to obtain permission directly from the copyright holder. To view a copy of this licence, visit http://creativecommons.org/licenses/by/4.0/ The Creative Commons Public Domain Dedication waiver (http://creativecommons.org/publicdomain/zero/1.0/) applies to the data made available in this article, unless otherwise stated in a credit line to the data. 
high-risk populations may not self-identify as such in household-based surveys. Therefore, global agencies such as the Joint United Nations Programme on HIV/ AIDS (UNAIDS), World Health Organization (WHO), President's Emergency Plan for AIDS Relief (PEPFAR), and the U.S. Centers for Disease Control and Prevention (CDC), encourage the implementation of more effective data collection strategies such as Biobehavioral Surveillance (BBS) surveys, which capture essential behavioral data linked to HIV infection among these groups. These data are then used to inform policy and programming [6]. Consistent with this focus on enhanced surveillance approaches, the National Strategic Plan for HIV and AIDS Response 2010-2014 (PEN III) in Mozambique recognized the disproportionate contribution of highrisk groups to the HIV epidemic and also noted the importance of systematizing the collection of evidence about these populations in order to enhance efforts toward epidemic control [7].

Between 2011 to 2014, the Mozambican Ministry of Health $(\mathrm{MoH})$, through the National Institute of Health (Instituto Nacional de Saúde - INS), has implemented five BBS surveys, each with the objective of collecting data on HIV prevalence, risk behaviors, access to and use of health services in these populations. The surveys focused on three key populations: female sex workers (FSW), men who have sex with men (MSM), and people who inject drugs (PWID), and two priority populations identified through consensus among key stakeholders: long-distance truck drivers (LDTD) and Mozambican workers in South African mines (MIN). Respondentdriven sampling (RDS) and time-location sampling (TLS) methodologies were used to recruit participants. A behavioral questionnaire was administered, and blood samples were collected for on-site rapid and centralized testing. The methodology and key results of each study have already been described in published reports and manuscripts. Most notably, these surveys provided the first prevalence estimates of HIV among these populations: MSM (3.7-8.2\%), FSW (17.8-31.2\%), PWID (19.9-50.1\%), LDTD (15.4\%), and MIN (22.3\%) [8-17]. Table 1 summarizes the information on the implementation of the five BBS surveys among key and priority populations in Mozambique, 2011-2014.

The experience gained from the implementation of these surveys has provided unique opportunities to not only enhance the availability of KP-related data in the country but also to strengthen the overall HIV surveillance system in Mozambique. Lessons learned from the implementation of the BBS surveys in Mozambique, Kenya and the Caribbean have been published and focus on recruitment methodology, laboratory testing procedures, data management and analysis, and human resource selection and training [18-20]. These insights have been useful to support the implementation of BBS in low-resource settings. The objective of this paper is to examine the BBS surveys in the context of their role in strengthening the HIV surveillance system. We document the lessons learned with coordination and collaboration; workforce development and institutional capacity building; data use and dissemination; advocacy and policy impact; and financial sustainability and community impact (Table 2).

\section{Main text \\ Lessons learned \\ Coordination \& collaboration}

Implementation of the BBS surveys has provided increased opportunities for multisectoral collaboration among host government entities (MoH, INS, Ministry of Labor and Provincial Health Departments), bilateral organizations (CDC, PEPFAR), multilateral agencies (UNAIDS), international academic research partners (UCSF), NGOs (ITECH, ICRH and Pathfinder International Population Services International) and civil society organizations: Association for Sexual Minority Rights in Mozambique (LAMBDA), FSW network (Tiyane Vavassate), and the National Network Against Drugs (UNIDOS). Government agencies were the stewards of the surveys, affirmed alignment with national strategic priorities, and endorsed the final results. There was gradual collaboration of government entities during the implementation process. For example, the National HIV/STI Control Program and the National Mental Health Program initially provided technical and programmatic input in the design of the surveys and eventually became principal investigators. Bilateral organizations, international academic research partner, multilateral agencies and NGOs all provided technical support, guaranteed alignment with global guidance, and the use of the latest innovative methodological approaches. In addition, the in-country NGOs provided logistical support. Civil society organizations provided contextual experience and an important link to the target populations. This participatory approach to collaboration with civil society was unprecedented in Mozambique for other national surveillance surveys and was critical for the success of the implementation of the surveys. This multi-sectoral involvement of various partners in the survey design and implementation, and dissemination of the findings has enhanced a sense of ownership of the data and set a precedence for meaningful collaboration between government agencies, technical assistance partners, and civil society organizations. For example, the multisectoral collaboration developed during the PWID study has been leveraged to support the development of a Harm Reduction Strategy drafted by the MoH-Mental Health Program and HIV/STI 


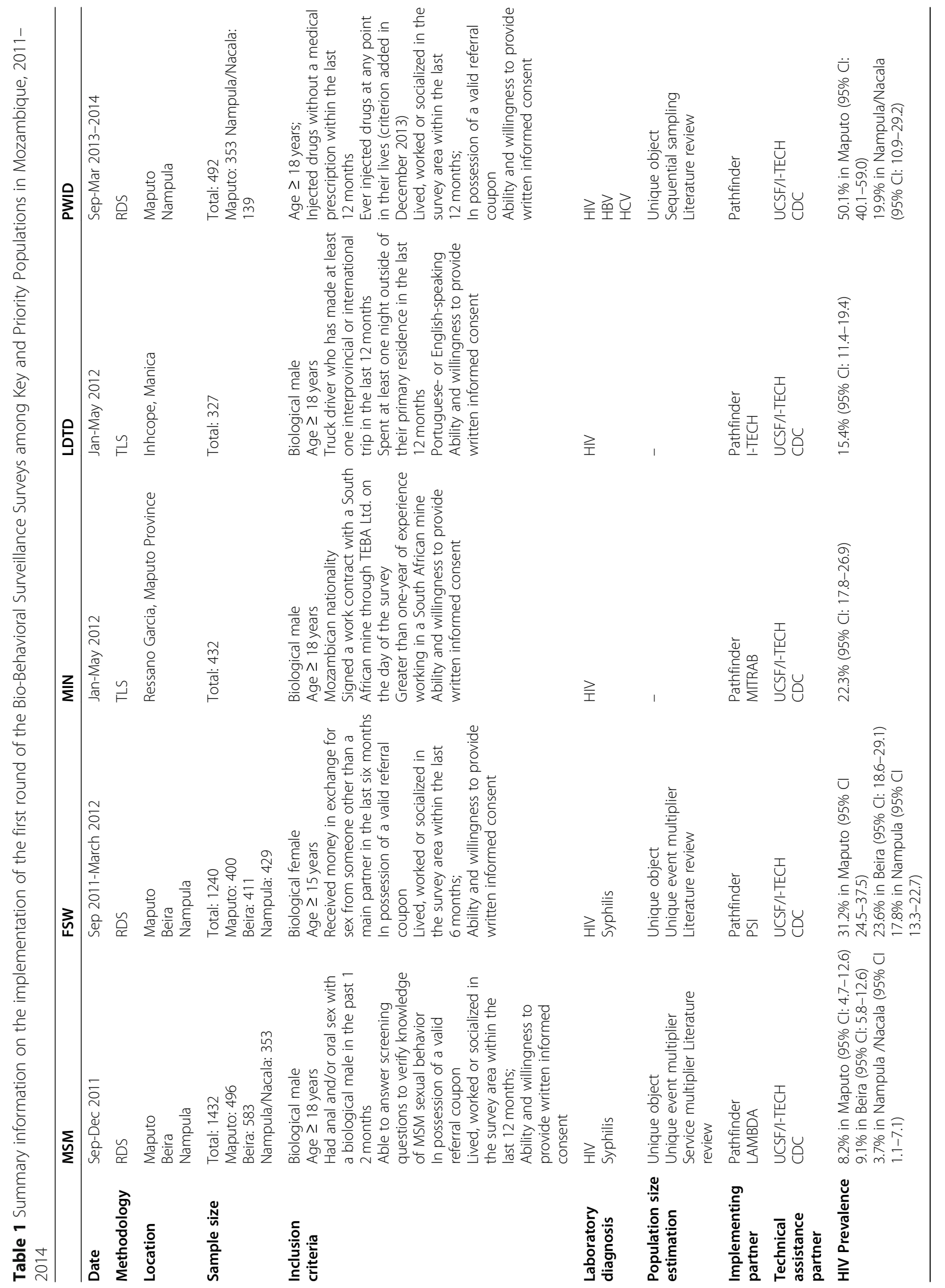


Table 2 Summary of lessons learned of the first round of the Bio-Behavioral Surveillance Surveys among Key and Priority Populations in Mozambique, 2011-2014

\begin{tabular}{|c|c|}
\hline Domain & Summary of lessons learned \\
\hline Coordination \& Collaboration & $\begin{array}{l}\text { - Government stewardship of survey implementation has affirmed alignment with national strategic } \\
\text { priorities } \\
\text { - Multisectoral collaboration enhanced ownership of survey results } \\
\text { - Collaboration with multilateral, bilateral and research entities ensured alignment with global } \\
\text { guidance and the use of the innovative methodological approaches } \\
\text { - Experience of multisectoral collaboration was leveraged for policy development }\end{array}$ \\
\hline $\begin{array}{l}\text { Workforce Development and } \\
\text { Institutional Capacity Building }\end{array}$ & $\begin{array}{l}\text { - Twining model and mentorship gradually increased local capacity for survey implementation } \\
\text { - Health informatics integrated into surveillance team to improve database development, mobile data } \\
\text { collection tools, data visualization and survey implementation monitoring } \\
\text { - Formalized data management practices and structures to ensure data access and use }\end{array}$ \\
\hline Data use and Dissemination & $\begin{array}{l}\text { - Increased participation in national and international conferences } \\
\text { - Data used for global reporting and national strategic planning } \\
\text { - Use of data by studies to for academic research (bachelor, master and PhD) } \\
\text { - Creation of Scientific Manuscript Advisory Panel to ensure scientific integrity }\end{array}$ \\
\hline Advocacy and Policy Impact & $\begin{array}{l}\text { - Strategic information produced to monitor the HIV response } \\
\text { - Development of Strategic Guidelines and Policy Documents. }\end{array}$ \\
\hline Financial Sustainability & $\begin{array}{l}\text { - Need to diversify funding sources to address high dependence on international donor organizations } \\
\text { - Flexible procurement and hiring mechanisms are required to implement surveys through } \\
\text { government system }\end{array}$ \\
\hline Community Impact & $\begin{array}{l}\text { - Enhanced visibility of KP } \\
\text { - KP ownership of the data for advocacy purposes } \\
\text { - Essential role of KP organizations as collaborators in the HIV response } \\
\text { - Capacity building of KP organizations has provided opportunities for additional funding opportunities } \\
\text { and technical collaborations }\end{array}$ \\
\hline
\end{tabular}

National Program, National AIDS Council, USAID and civil society.

The roles of the various collaborators were defined at the outset via a memorandum of understanding. The implementation of the surveys has been coordinated by a technical working group (TWG) with members from key stakeholders. The TWG is organized into subcommittees responsible for areas such as general coordination, administration and logistics, survey methods, laboratory procedures, data management, and data analysis. The TWG meets bi-weekly and regularly schedules work sessions to focus on key outputs such as protocol development, data analysis, and report writing.

\section{Workforce development and institutional capacity building} One major impact of ongoing BBS survey implementation has been gradual workforce development at the INS and $\mathrm{MoH}$ and institutional capacity building evidenced by increasingly complex systems that support data management and use.

Technical assistance for the implementation of the BBS was initially based on a twinning model whereby technical advisors were hired by international donors and provided direct mentorship to national INS and $\mathrm{MoH}$ staff. To date, twinning has focused on building capacity of principal investigators, survey coordinators, data managers, and data analysts. Twinning has helped these individuals gain the knowledge and skills necessary to take on increasingly sophisticated roles of leadership within the INS and $\mathrm{MoH}$ over the years. As an example, the national BBS coordinator transitioned from a role of coordinating single surveys to the role of coordinator of the entire INS unit responsible for large national surveys and initiatives.

As the roles and experiences of INS and MoH staff increased and became more complex, so too did the vision of the types of skills necessary to support the implementation of high-quality surveys. For example, informatics specialists were hired to become involved in more hightech surveillance activities that focus on providing technical assistance in database development, mobile data collection tools, data visualization and survey implementation monitoring.

The need to guarantee the proper management of BBS data coincided with a broader conversation about data management practices and structures at INS. As a result, the institution established a Data Management Unit (DMU), which manages a central data repository of all survey and surveillance data generated by INS. The DMU is staffed by data managers, statisticians, and informatics specialists, who are responsible for drafting data management and security policies, providing analysis support to various research and surveillance activities, producing reports, infographics, and supporting a website displaying summary information from key data sources. DMU staff are members of the BBS TWG and are involved in the planning, coordination, and daily implementation of the surveys. 
Finally, INS implementation role has expanded over the years from governmental collaborator to primary implementor. Experience with the BBS surveys positioned INS as the key institution to lead the Mozambican arm of a multi-country study funded by the International Organization for Migration (IOM) focusing on miners and their communities [21]. Subsequent studies that have benefited from the human resources, institutional structures and experience gained through the implementation of BBS include the TB Prevalence Survey, Violence Against Children Survey (VACS), Service Availability and Readiness Assessment (SARA), and the upcoming Population-Based HIV Impact Assessment (PHIA) survey.

\section{Data use and dissemination}

Upon completing preliminary data analysis, the findings were shared with local stakeholders through community forums, and concise brochures developed in Portuguese and English for use during partner outreach activities. A final national report was then prepared, based upon additional data analyses and stakeholder input [8-12]. Results were also shared with other government institutions, such as Mozambique's National AIDS Council (Conselho Nacional de Combate ao HIV/SIDA) and the National HIV/STI Control Program. Findings have also been disseminated at local, national, and international scientific conferences through poster and oral presentations [22-32]. Although communicating findings to the government, donors, and service delivery partners has been successful, and despite strong collaborations with central-level civil society organizations, sharing results with large numbers of key populations especially subgroups within these key populations throughout the country (ex: high-income FSW, PWID and MSM or married MSM who may be stigmatized in their communities by their sexual behaviors) - has been a challenge due to the lack of formal networks and community organizations, especially outside of urban centers.

The data has also been used for global reporting and national target setting particularly for Global AIDS Response Progress Reporting (GARPR) and Global AIDS Monitoring (GAM), HIV prevalence and incidence estimates based on the UNAIDS-supported Spectrum package, Global Fund Proposals and PEPFAR annual plans, as well as global campaigns such as the "All In" initiative, focusing on HIV among adolescents and youth [33].

There has been a systematic approach to the use and dissemination of data for the development of abstracts for international conferences and manuscripts for international peer-reviewed journals of both INS staff and students interested in using the BBS data for their thesis and dissertation work. To date, sixteen manuscripts have been published or are under review in peer-reviewed journals [13-17, 34-44], and six students have used BBS data for their dissertations (undergraduate, masters, and doctorate). These abstracts and manuscripts have benefited from systematic and ongoing support from INS leadership and partner organizations.

To promote the analysis and dissemination of BBS scientific documents such as abstracts, manuscripts, presentations, reports, policy briefs, and brochures, the Mozambique BBS Scientific Manuscript Advisory Panel was established in 2012. This advisory panel provides oversight to ensure appropriate use of data, reviews analysis proposals to ensure scientific integrity and to avoid duplication. It was initially composed of representatives from INS, donor agencies and international research partners. Panel membership is periodically reviewed to ensure representation of the institutions leading the design and development of BBS in Mozambique. The advisory panel convenes quarterly and organizes ad hoc meetings when necessary. A data sharing policy was approved between INS and CDC in 2015, further cementing its role and institutional function. This data sharing policy was created to ensure that the data collected for BBS are used and disseminated widely and appropriately and that BBS investigators can fairly participate in the process of publishing findings, while also ensure the integrity of the use of survey data. The policy also provides guidance on data access procedures for investigators and other entities not already granted direct access to the study datasets for purposes of preparing final survey reports as described in individual BBS protocols. This data sharing policy is the first of its kind for HIV surveillance studies in Mozambique and is being used to support the development of a more generalized inter-institutional data sharing policy that encompasses the use and dissemination of various survey and surveillance activities led by INS. Unfortunately, however, the advisory panel is no longer active because it's aims were not prioritized as result of staff turn-around of key collaborators. This highlights the importance of institutionalizing such structures.

\section{Advocacy and policy impact}

These BBS surveys in Mozambique produced the first HIV prevalence estimates among key populations in the country and have been used to support strategic information needs, and to identify prevention and treatment program gaps. The results of these surveys also provided the evidence necessary for key stakeholders to effectively monitor and evaluate HIV interventions and strategies directed to these populations This is exemplified by the National HIV/STI Control program's use of BBS results to establish treatment guidelines for KPs and promote KP-friendly health provider trainings to address issues 
related to stigma found in the healthcare setting [45]. The National HIV program also led a recent triangulation exercise using BBS results to estimate the size of the three key population groups throughout the country, disaggregated by district. The results have been used to allocate resources, set programmatic targets and model the impact of targeted key population HIV interventions.

In addition to the use of data to identify programmatic gaps and to create the evidence base necessary for new policies, they have also been used as a powerful advocacy tool. For example, a policy brief including recommendations based on the findings from the PWID survey was produced and used by the National Mental Health Program as evidence to advocate for the introduction of harm-reduction interventions in the country. The National AIDS Council (Conselho Nacional de Combate ao $H I V / S I D A, C N C S)$ is also using the data to advocate for the inclusion of key populations as part of the Prevention Roadmap.

\section{Financial sustainability}

The majority of funding for the implementation of the first five BBS has been through PEPFAR via CDC and their partners. Financial support has also extended to technical and implementation support which has strengthened the quality of implementation. The second round of BBS among FSW is funded by the Global Fund to Fight AIDS, Tuberculosis, and Malaria, with lab supplies purchased by CDC; UCSF continues to provide technical assistance. Unlike the collaboration with CDC during the first round of BBS, which was characterized by significant technical involvement by CDC staff and partners, the Global Fund has followed a classical donor role with limited technical involvement in the design and implementation of the surveys. This has required the BBS implementation team to learn about Global Fund policies as well as those unique to $\mathrm{MoH}$ in order to access funds for administrative and logistic processes. INS contributes through human resources and infrastructural support and provides general scientific oversight to ensure alignment with the objectives of the National Strategic Plan for HIV and AIDS Response. Behavioral surveillance staff also led the development of key sections of the Global Fund Proposals pertaining to research and surveillance. Despite these gains, however, the PEPFAR Sustainability Index, which monitors national investments and the sustainability landscape, highlighters that there are no domestic public or private sector funds supporting the BBS [46]. As such, there is a recognized need to diversify funding sources, however, the economic crisis in Mozambique limits the government's ability to fund these activities at present. Finally, all future studies will include a financial evaluation to assess whether budgeted costs were met or exceeded in order to track spending and ensure the cost-effective use of limited resources.

From a practical perspective, financial structures need to be reviewed in line with the unique needs of the surveys. For example, the procurement of certain items used as "unique objects" for population size estimation e.g., key chain flashlights, make-up kits, and hygiene kits - are difficult to acquire given the MOH/INS procurement policies which necessitate a labor-intensive and time-consuming public bidding process that requires constant communication and collaboration between the supplier and study coordinators. Hiring policies have also posed a challenge. For example, there is a need to hire a different set of staff for the formative and RDS phases of the survey who have specialized training, background, and skill sets. However, $\mathrm{MoH}$ considers the BBS surveys to be one unique study and, therefore, requires that the staff be the same throughout, which has had an impact on the appropriateness of short-term staff being hired. Shifts in the global economic landscape and political commitment suggest that fewer resources will be available that can be dedicated to surveillance activities, further constraining future survey implementation.

\section{Community impact}

The BSS surveys helped to increase the visibility of KP in Mozambique, enhanced data use for advocacy purposes, strengthened institutional capacity of KP organizations and ensured their collaboration in program implementation and strategic decision making.

Before the BBS surveys, KP were largely hidden due to stigma and discrimination. However, the results of the survey confirm the presence of these high-risk groups in Mozambique, who have taken ownership of the data and consistently use the results for advocacy. For example, the Platform for the Rights of Sex Workers network, formed after the implementation of the BSS-FSW survey, released a position paper in July 2020 where they used the results of the BBS to provide background on the situation of FSW in Mozambique and advocated for renewed commitment to human rights and social protections for sex workers in the context of the COVID-19 pandemic [47].

The KP organizations representing MSM, FSW and PWID were key collaborators in the design, implementation, analysis and dissemination of the survey findings. They received financial support to engage their peer educators in recruitment processes and provided important field oversight to implementation. As a result, these organizations have gone on to receive additional opportunities to engage in KP-specific surveys [48] and program implementation. However, the organizations still face structural challenges. For example, LAMBDA, an association for the LGBT network in Mozambique, is not yet 
legally recognized as a formal association and is therefore unable to receive the funding necessary to be a prime recipient of funding intended for the enhanced engagement of MSM in HIV care and treatment and therefore their contributions to the design and implementation of programming remains limited.

Finally, the meaningful engagement of KP associations is now a key element of the HIV Response.

KP organizations figure prominently in the development of the upcoming 5th National Strategic Plan for the HIV/AIDS Response (2021-2025). In addition, they are permanent members of the Country Coordinating Mechanisms of the Global Fund and are also members of the Oversight Committee charged with overseeing the programmatic and financial performance of grants financed by the Global Fund to ensure that the human and financial resources are used efficiently and effectively.

\section{Conclusion}

Mozambique's first experience with the design, implementation, and analysis of BBS surveys has contributed significantly to national understanding of the behavioral factors contributing to HIV transmission among key and priority populations in the country. The lessons learned provide opportunities for other limited resource settings to reflect on strategies to improve the implementation of surveys. However, the impact on strengthening the HIV surveillance system and the HIV Response should not be underestimated. The data has rendered previously hidden populations visible and resulted in enhanced capacity building, advocacy, and the development of policies and guidelines for collaboration and improved quality of care. In order to leverage the gains experienced and further systematize the lessons learned, there is a need to develop a National HIV Surveillance Plan that integrates all HIV surveillance activities under one coordinating body and emphasizes enhanced capacity of key areas, such as laboratory procedures. Such a plan must also emphasize continual human resource capacity building in the area of data analysis to support strategic planning. In addition, the importance of cultivating partnerships at the district level will guarantee the dissemination of findings to individuals who may not be connected with established key population networks and organizations. Finally, BBS surveys play an important role in providing strategic information about marginalized groups and future surveys should include other stigmatized communities, such as transgender persons, to ensure a comprehensive HIV Response. Given that traditional surveillance methodologies from routine data often do not capture hidden populations, which continue to disproportionately contribute to the HIV epidemic, it will be important to ensure that BBS surveys remain an integral element of ongoing HIV surveillance activities in Mozambique.

\section{Abbreviations \\ BBS: Biological and behavioral survey; CDC: Centers for Disease Control and Prevention; FSW: Female sex workers; GAM: Global AIDS Monitoring; GARP R: AIDS Response Progress Reporting; HIV: Human immunodeficiency virus; ICRH: The International Centre for Reproductive Health, INS: Instituto Nacional de Saúde (National Institute of Health); ITECH: The International Training and Education Center for Health; KP: Key population; \\ LAMBDA: Association for sexual minority rights in Mozambique; LDTD: Long- distance truck drivers; MIN: Mozambican workers in South African mines; MoH: Ministry of Health; MSM: Men who have sex with men; NGO: Non- governmental organization; PEN: National Strategic Plan for HIV and AIDS Response; PEPFAR: President's Emergency Plan for AIDS Relief; PHIA: Population-based HIV impact assessment; PWID: People who inject drugs; RDS: Respondent-driven sampling; SARA: Service Availability and Readiness Assessment; STI: Sexually Transmitted Infection; TLS: Time-location sampling; TWG: Technical Working Group; UCSF: University of California in San Francisco; UNAIDS: Joint United Nations Programme on HIV/AIDS; UNIDOS: National Network Against Drugs; VACS: Violence Against Children Survey}

\section{Acknowledgements}

The authors would like to thank all who contributed to the planning, implementation, analysis and dissemination of the studies- investigators, study team, NGOs other members of civil society, and the National HIV/STD program. In addition, we would like to thank Laura Cooley of the Epidemic Intelligence Service at CDC-Atlanta for her support with the initial assessment of BBS implementation. Finally, we would like to thank Dr. Stanley Luchters for his critical review of the manuscript.

\section{Authors' contributions}

CB conceptualized and wrote the manuscript. MB supported project implementation and provided critical revision. DCL coordinates the project. IS supported project implementation. RH supported project implementation and provided critical revision. PY, NS and HRM provided critical revisions. All authors equally contributed to writing from their own perspectives and editing the manuscript and approved the final manuscript.

\section{Funding}

This paper used data from research supported by the President's Emergency Plan for AIDS Relief (PEPFAR) through the U.S. Centers for Disease Control and Prevention (CDC) Mozambique Country Office under the terms of Cooperative Agreement Number \#5U2GPS002829. The findings and conclusions in this article are those of the authors and do not represent the official position of the funding agencies.

\section{Availability of data and materials}

All studies information and data sets are fully available at the Mozambique National Institute of Health (INS) data repository for researchers who meet the criteria for access to confidential data. Data are from the BBS study's whose authors may be contacted through: www.ins.gov.mz.

\section{Ethics approval and consent to participate}

All surveys were approved by the National Bioethics Committee for Health (CNBS) in Mozambique, the Committee on Human Research (CHR) at the University of California, San Francisco (UCSF) and by the Division of Global HIV/AIDS of the U.S. Centers for Disease Control and Prevention, Atlanta. In all surveys, written informed consent was obtained from the participants.

\section{Consent for publication}

Not applicable.

\section{Competing interests}

The authors declare that they have no competing interests.

\section{Author details}

${ }^{1}$ Instituto Nacional de Saúde (INS), Maputo, Mozambique. ${ }^{2}$ Department of Public Health and Primary Care, Faculty of Medicine and Health Sciences, Ghent University, Ghent, Belgium. ${ }^{3}$ HIV and STI Program, Public Health 
Directorate, Ministry of Health, Maputo, Mozambique. ${ }^{4}$ Centers for Disease Control and Prevention, Atlanta, USA. ${ }^{5}$ Centers for Disease Control and Prevention, Maputo, Mozambique. ${ }^{6}$ University of California, San Francisco (UCSF), San Francisco, USA. '`School of Public Health, Rutgers University, Piscataway, NJ, USA.

Received: 14 June 2020 Accepted: 21 December 2020

Published online: 07 January 2021

\section{References}

1. Ministério da Saúde (MISAU), Instituto Nacional de Estatística (INE), ICF. Inquérito de Indicadores de Imunização, Malária e HIV (IMASIDA), 2015. Maputo. Rockville: EUA: INS, INE, e ICF; 2015. Available from: https:// dhsprogram.com/pubs/pdf/AIS12/AIS12.pdf. Accessed 4 Nov 2020.

2. Instituto Nacional de Saúde (INS), Instituto Nacional de Estatística (INE), ICF Macro. Inquerito Nacional de Prevalencia, Riscos Comportamentais e Informação sobre o HIV e SIDA em Moçambique 2009. Calverton: EUA: INS, INE e ICF Macro; 2010. Available from: https://dhsprogram.com/pubs/pdf/ ais8/ais8.pdf. Accessed 4 Nov 2020.

3. García-Calleja JM, Gouws E, Ghys PD. National population based HIV prevalence surveys in sub-Saharan Africa: results and implications for HIV and AIDS estimates. Sex Transm Infect. 2006;82(Suppl 3):64-70.

4. Salomon JA, Murray CJ. Modelling HIV/AIDS epidemics in sub-Saharan Africa using seroprevalence data from antenatal clinics. Bull World Health Organ. 2001;79(7):596-607.

5. Multi-sectoral Technical Working Group for Monitoring and Evaluation Distribution of the incidence of HIV infections in the 15- to 49-year-old population in Mozambique by mode of transmission, 2013. 2014.

6. Malekinejad M, Johnston LG, Kendall C, Kerr LRFS, Rifkin MR, Rutherford GW. Using respondent-driven sampling methodology for HIV biological and behavioral surveillance in international settings: a systematic review. AIDS Behav. 2008;12(1):105-30.

7. CNCS. Relatório de Avaliação do Plano Estratégico Nacional de Combate ao HIV e SIDA 2010-2014. Maputo, Moçambique. Available from: https://erc. undp.org/evaluation/documents/download/8524. Accessed 4 Nov 2020.

8. INS, CDC, Pathfinder International, I-TECH. Final report: the integrated biological and behavioral survey among female sex workers, Mozambique 2011-2012. Maputo; 2013. Available from: https://globalhealthsciences.ucsf. edu/sites/globalhealthsciences.ucsf.edu/files/pub/ibbs-fsw-final-report.pdf. Accessed 4 Nov 2020.

9. INS, CDC, UCSF Global Health Science, DPS Manica, CIDI, Pathfinder International, et al. Final Report: The Integrated Biological and Behavioral Survey among Long Distance Truck Drivers, 2012. Maputo; 2012. Available from: https://globalhealthsciences.ucsf.edu/sites/globalhealthsciences.ucsf. edu/files/pub/ibbs-long-distance-truck-drivers-final-report.pdf. Accessed 4 Nov 2020.

10. INS, CDC, UCSF, PSI, Pathfinder International, I-TECH, et al. Final report: the integrated biological and behavioral survey among men who have sex with men, Mozambique, 2011. Maputo; 2013. Available from: https:// globalhealthsciences.ucsf.edu/sites/globalhealthsciences.ucsf.edu/files/pub/ ibbs-msm-final-report.pdf. Accessed 4 Nov 2020.

11. INS, CDC, UCSF Global Health Science, MITRAB, I-TECH. Final Report: The Integrated Biological and Behavioral Survey among Mozambican Workers in South African Mines, 2012. Maputo; 2013. Available from: https:// globalhealthsciences.ucsf.edu/sites/globalhealthsciences.ucsf.edu/files/pub/ pwid-final-report-20180329.pdf. Accessed 4 Nov 2020.

12. MISAU, INS. Final report: the Mozambique integrated biological and behavioral survey among people who inject drugs, 2014. Maputo; 2017. Available from: https://globalhealthsciences.ucsf.edu/sites/ globalhealthsciences.ucsf.edu/files/pub/pwid-final-report-20180329.pdf. Accessed 4 Nov 2020.

13. Botão C, Horth RZ, Frank H, Cummings B, Inguane C, Sathane I, et al. Prevalence of HIV and associated risk factors among long distance truck drivers in Inchope, Mozambique, 2012. AIDS Behav. 2016;20(4):811-20.

14. Augusto ÂR, Young PW, Horth RZ, Inguane C, Sathane I, Ngale K, et al. High burden of HIV infection and risk behaviors among female sex Workers in Three Main Urban Areas of Mozambique. AIDS Behav. 2016;20(4):799-810.

15. Nalá R, Cummings B, Horth R, Inguane $C$, Benedetti M, Chissano $M$, et al. Men who have sex with men in Mozambique: identifying a hidden population at high-risk for HIV. AIDS Behav. 2015;19(2):393-404.
16. Semá Baltazar C, Horth R, Boothe M, Sathane I, Young P, Langa DC, et al. High prevalence of HIV, HBsAg and anti-HCV positivity among people who injected drugs: results of the first bio-behavioral survey using respondentdriven sampling in two urban areas in Mozambique. BMC Infect Dis. 2019; 19(1):1022.

17. Baltazar CS, Horth R, Inguane C, Sathane I, César F, Ricardo H, et al. HIV prevalence and risk behaviors among Mozambicans working in South African mines. AIDS Behav. 2015;19(Suppl 1):S59-67.

18. Volkmann T, Chase M, Lockard AM, Henningham D, Albalak R. Lessons learned from the implementation of HIV biological-behavioral surveys of key populations in the Caribbean. AIDS Educ Prev. 2018;30(6):528-41.

19. UCSF Global Health Science. Implementing integrated bio-behavioral surveys among key populations at higher risk of HIV exposure with an emphasis in respondent driven sampling - lessons learned from the field. 2012. Available from: https://globalhealthsciences.ucsf.edu/sites/ globalhealthsciences.ucsf.edu/files/gsi-ibbs-lessons-learned-may-2012.pdf. Accessed 4 Nov 2020.

20. Okal J, Raymond HF, Tun W, Musyoki H, Dadabhai S, Broz D, et al. Lessons learned from respondent-driven sampling recruitment in Nairobi: experiences from the field. BMC research notes. 2016;9(1):158.

21. Semá Baltazar C, DeLima YV, Ricardo H, Botão C, Chitsondzo Langa D, da Costa $\mathrm{P}$, et al. HIV prevalence and TB in migrant miners communities of origin in Gaza Province, Mozambique: the need for increasing awareness and knowledge. PLoS One. 2020;15(4):e0231303.

22. Teodoro E, Boothe M, Baltazar C, Young P, Frank H, Sathane I, et al. Urgent need for harm-reduction interventions in Mozambique: results from the integrated bio-behavioral survey among people who inject drugs. Vancouver; 2015.

23. Augusto A, Young P, Ngale K, Inguane C, Sathane I, Horth R, et al. Risk factors associated with HIV infection among female sex workers in the three main urban areas of Mozambique, 2011-2012: results from an RDS survey. Presented in the 7th HIV Pathogenesis, Treatment and Prevention (IAS 2013), held in Kuala Lumpur, Malaysia.

24. Ngale K, Benedetti M, Horth R, Cummings B. Perfil sociodemográfico de Trabalhadoras de sexo (MTS): Resultados do Primeiro Inquérito Biológico Comportamental em Moçambique. Presented in XIV Jornádas Nacionais de Saúde (2012), held in Maputo, Moçambique.

25. Semá Baltazar C, Young P, Inguane C, César F, Horth R, Raymond HF. HIV prevalence and risk factors among Mozambican mineworkers working in South Africa, 2012. Presented in the 7th HIV Pathogenesis, Treatment and Prevention (IAS 2013), held in Kuala Lumpur, Malaysia.

26. Botão C, Frank H, Young P, Cummings B, Inguane C, Sathane I, et al. HIV prevalence and prevention behavior among long-distance truck drivers passing through a major truck stop in Central Mozambique, 2012. Presented in the 7th HIV Pathogenesis, Treatment and Prevention (IAS 2013), held in Kuala Lumpur, Malaysia.

27. Nala R, Lane T, Inguane C, Horth R, Mirjahangir J, Young P, et al. HIV prevalence and population size estimation among men who have sex with men in three cities in Mozambique, 2011. Presented in the 7th HIV Pathogenesis, Treatment and Prevention (IAS 2013), held in Kuala Lumpur, Malaysia.

28. Ngale K, Benedetti M, Horth R, Young P, Cummings B, Sathane I, et al. HIV prevalence among female sex workers: results from the integrated biobehavioral survey in Mozambique. Presented in the 5th Africa Conference on Sexual Health \& Rights (2012), held in Windhoek, Namibia.

29. Semá Baltazar C, Horth R, Cooley L, Young P, Inguane C, Sathane I, et al. HIV and the Mozambican mineworker working in South Africa: the undiagnosed, the unprotected, and the uncircumcised. Presented in the 17th International Conference on AIDS and STIs in Africa (ICASA 2013), held in Cape Town, South Africa.

30. Semá Baltazar C, Sathane I, Horth R, Boothe M, Peregoy J, Frank H, et al. High HIV, HBV, and HCV prevalence among people who inject drugs: results from the first integrated bio-behavioral survey of PWID in Mozambique. Presented in the 18th International Conference on AIDS and STIs in Africa (ICASA 2015), held in Harare, Zimbabwe.

31. Inguane C, Young P, Frank H, Horth R, Ngale K, Sathane I, et al. Estimating the population size of female sex workers in the three main urban areas of Mozambique, 2011-2012. Presented in the 7th HIV Pathogenesis, Treatment and Prevention (IAS 2013), held in Kuala Lumpur, Malaysia.

32. Sathane I, Horth R, Boothe M, Baltazar C, Young P, Raymond HF, et al. Estimating the number of people who inject drugs (PWID) in two urban 
areas in Mozambique using four different methods, 2014. Presented in the 8th HIV Pathogenesis, Treatment and Prevention (IAS 2015), held in Vancouver, Canada.

33. UNICEF. All In to \#EndAdolescentAIDS. 2015 https://www.pepfar.gov/ documents/organization/270539.pdf. Accessed 4 Nov 2020.

34. Cummings B, Horth R, McFarland W, Lane T, Young PW, Nalá R, et al. Bisexual and bidirectional: assessing the potential for HIV bridging in Mozambique. AIDS Behav. 2018;22(7):2189-98.

35. Horth RZ, Cummings B, Young PW, Mirjahangir J, Sathane I, Nalá R, et al. Correlates of HIV testing among men who have sex with men in three urban areas of Mozambique: missed opportunities for prevention. AIDS Behav. 2015;19(11):1978-89.

36. Martins-Fonteyn E, Loquiha O, Baltazar C, Thapa S, Boothe M, Raimundo I, et al. Factors influencing risky sexual behaviour among Mozambican miners: a socio-epidemiological contribution for HIV prevention framework in Mozambique. Int J Equity Health. 2017;16(1):179.

37. Sathane I, Horth R, Young P, Inguane C, Nalá R, Miranda AE, et al. Risk factors associated with HIV among men who have sex only with men and men who have sex with both men and women in three urban areas in Mozambique. AIDS Behav. 2016;20(10):2296-308.

38. Ngale K, Cummings B, Horth R. Unseen, unheard and unprotected: prevalence and correlates of violence among female sex workers in Mozambique. Cult Health Sex. 2019;21(8):898-913.

39. Semá Baltazar C, Boothe M, Kellogg T. Young people who inject drugs in Mozambique: should we emphasize them in the National Harm Reduction Plan? Harm Reduct J. 2020;17(1):20.

40. Semá Baltazar C, Boothe M, Kellogg T, Ricardo P, Sathane I, Fazito E, et al. Prevalence and risk factors associated with HIV/hepatitis B and HIV/hepatitis $\mathrm{C}$ co-infections among people who inject drugs in Mozambique. BMC Public Health. 2020;20(1):851.

41. Sathane I, Boothe MAS, Horth R, Baltazar CS, Chicuecue N, Seleme J, et al. Population size estimate of men who have sex with men, female sex workers and people who inject drugs in Mozambique-a multiple methods approach. Sex Transm Dis. 2020;47(9):602-9.

42. Boothe M, Sathane I, Baltazar Semá C, Chicuecue N, Horth R, Fazito E, et al. Low engagement in HIV services and Progress through the treatment Cascade among key populations living with HIV in Mozambique: alarming gaps in knowledge of status. BMC Public Health. 2020; Available from: https://www.researchsquare.com/article/rs-28468/v1.

43. Boothe MAS, Comé C, Semá Baltazar C, Chicuecue N, Seleme J, Chitsondzo Langa $\mathrm{D}$, et al. High burden of self-reported sexually transmitted infections among key populations in Mozambique: the urgent need for an integrated surveillance system. BMC Infect Dis. 2020;20(1):636.

44. Boothe M, Semá Baltazar C, Sathane I, Raymond HF, Fazito E, Temmerman M. et al, Young Key Populations Left Behind: The Necessity for a Targeted Response in Mozambique. BMC Public Health. 2020; Available from: https:// www.researchsquare.com/article/rs-46045/v1.

45. MISAU, Direcção Nacional de Assistência Médica (DNAM), PNC ITS-HIV/SIDA. Directriz para Integração dos Serviços de Prevenção, Cuidados e Tratamento do HIV/SIDA para a População-chave no Sector da Saúde. 2016. Available from: https://www.misau.gov.mz/index.php/directrizes-nacionais?download= 134:directriz-para-integracao-dos-servicos-de-prevencao-cuidados-etratamento-do-hiv-e-sida-para-a-populacao-chave-no-sector-da-saude. Accessed 4 Nov 2020.

46. Mozambique Sustainability Index and Dashboard 2019. Available from: https://www.state.gov/wp-content/uploads/2019/12/Mozambique-SID-2019. pdf. Accessed 4 Nov 2020

47. Platform for the Rights of Sex Workers in Mozambique. Position Paper of the Platform for the Rights of Sex Workers in Mozambique in the context of COVID-19. Available from: https://aidsfonds.org/cms/sites/default/files/inlinefiles/Position\%20Paper\%20Plataforma\%20Final\%20Eng_0.pdf. Accessed 4 Nov 2020.

48. CIOB, INS, UNC, FHI360. Mapeamento Programático e Prevalência de HIV entre Populações Chave em 5 Províncias de Moçambique: Estudo PLACE 2017. Chapel Hill: UNC CIOB FHI360; 2018. Available from: https://www.fhi36 0.org/sites/default/files/media/documents/resource-linkages-portuguesemozambique-report-august-2018.pdf. Accessed 4 Nov 2020.

\section{Publisher's Note}

Springer Nature remains neutral with regard to jurisdictional claims in published maps and institutional affiliations.

\section{Ready to submit your research? Choose BMC and benefit from:}

- fast, convenient online submission

- thorough peer review by experienced researchers in your field

- rapid publication on acceptance

- support for research data, including large and complex data types

- gold Open Access which fosters wider collaboration and increased citations

- maximum visibility for your research: over $100 \mathrm{M}$ website views per year

At $\mathrm{BMC}$, research is always in progress.

Learn more biomedcentral.com/submissions 